\title{
ESCANER LASER: MODELO 3D Y ORTO IMÁGENES ARQUITECTÓNICAS DE LA IGLESIA DE SANTA MARIA DEL MAR EN BARCELONA
}

\author{
Ajandro Marambio \\ Alejandro.E.Marambio@upc.edu \\ Dra. Pilar García Almirall \\ pilar.garcia-almirall@upc.edu \\ Universitat Politécnica de Catalunya, \\ Av. Diagonal 649, \\ 08028, Barcelona, SPAIN
}

Remisión articulo: 20-9-2006 Remisión definitiva: 22-9-2006

Palabras Clave: Laser Scanner, Heritage, Digital Documentation, 3D, Orthoimage

Resumen: El objetivo del Proyecto de escaneo de la iglesia de Santa Maria 2006, fue la generación de planos en CAD 2D como orto-imágenes de la recogida del modelo de nube de puntos en 3D en un periodo de tres meses. Esta nube de puntos trabaja como base de datos para la preservación del monumento investigado. Un volumen de trabajo general para obtener alta calidad, se propone una alta resolución del plano de la orto-imagen basado en la posibilidad dada de la explotación de los datos de nubes de puntos de alta densidad. La generación de superficies trianguladas se evita debido a una significante reducción del tiempo de post procesamiento.

\section{Objetivos}

El Departamento de Cultura de la Generalitat de Cataluña a través de su área de Patrimonio Arquitectónico requería de la planimetría del estado actual de la Iglesia de Santa María del Mar para su futura restauración. Debido al poco tiempo que existía para el desarrollo del proyecto y la necesidad de contar con una gran cantidad de información fiable, se optó realizar el levantamiento arquitectónico por medio de la tecnología del escáner láser terrestre.

Este proyecto fue realizado a través del Laboratorio de Modelización Virtual de la Ciudad (LMVC) de la Universidad Politécnica de Cataluña. El LMVC lleva más de tres años en la investigación y desarrollo de usos y aplicaciones de la tecnología láser en el registro del Patrimonio Arquitectónico. El levantamiento con láser escáner se realizó como una alternativa a un levantamiento con topografía tradicional para realizar planos CAD en un periodo de tres meses a partir de febrero del 2006: el primer mes se utilizó para la captura de datos, el segundo mes se usó en el post proceso de los datos adquiridos y el último mes se utilizó en la explotación del modelo de nube de puntos 3D. Solo fue necesaria la participación de dos técnicos para realizar el proyecto completo.

La documentación final presentada como registro de Santa Maria del Mar incluyó:

- Un modelo de nube de puntos georeferenciado de alta resolución y alta precisión. Estructurado en varias partes y con dos resoluciones: una válida para la escala 1:200,1:100 de $5 \mathrm{~cm}$, y otra válida para la escala 1:50,1:25 de $3 \mathrm{~cm}$ de las zonas más significativas. 
- Orto-imágenes arquitectónicas de plantas, secciones y alzados para su incorporación en programas comerciales de CAD.

\section{Metodología}

Como parte de la tesis doctoral en desarrollo para el Centro de Política de Suelo y Valoraciones (CPSV) se presenta una aproximación al proceso de levantamiento con láser escáner para la generación de planos arquitectónicos, a través de orto-imágenes de nubes de puntos con altas densidades. Esta metodología plantea lo innecesario de transformar modelos complejos de nubes de puntos a modelos de mallas texturizados para la generación de planos válidos.

Son varias las investigaciones existentes sobre aplicaciones de láser escáner que se han centrado en la generación de polígonos a partir de las nubes de puntos para la extracción de vértices en la búsqueda de la generación de planos arquitectónicos ya sea de una manera automática o semi-automática ${ }^{12}$. Esto implica un proceso largo, complicado e impreciso en la escala que maneja el Patrimonio Arquitectónico. Su gran complejidad requiere la intervención de técnicos especializados en la interpretación de los datos que se capturan en todo el proceso. Todavía es necesario dividir y estructurar la información para diferenciar entre elementos decorativos, elementos estructurales, singularidades, mobiliario, etc. que se presentan en un edificio arquitectónico.

La mayoría de las veces se llega a obtener mejores resultados a través de técnicas de fotogrametría que permite una detección de vértices más sencilla y en menor tiempo, no por la técnica en sí, sino por que la interpretación hecha por un especialista es más simple. Sin embargo una desventaja significativa de esta técnica es la imposibilidad de hacer secciones. El levantamiento con láser escáner supera esta barrera al convertir la realidad en coordenadas espaciales. Lo que permite en un entorno digital visualizar cualquier vista o sección que se necesite, ya sea ortogonal o en perspectiva del modelo 3D.

Como resultado de la investigación se elaboró una metodología que incluye las siguientes etapas:

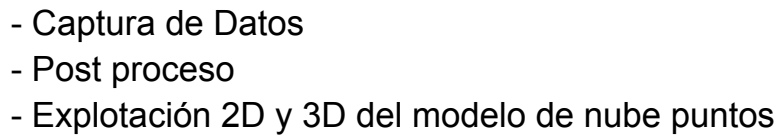

Fig. 1. Metodología para la generación de orto imágenes

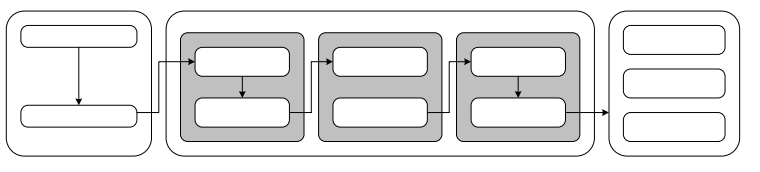

\footnotetext{
1 Allen, P., 2003. New Methods of Digital Modeling of Historic Sites. 3D Reconstruction and Visualization. IEEE Computer Society Nov/Dec 2003.

${ }^{2}$ Ballzani M, 2004. Laser Scanner 3D Survey in Archaeological Field: the Forum Of Pompeii. International Conference on Remote Sensing Archaeology. Beijing, CHINA.
} 


\section{Captura de Datos}

Lo primero que se tiene que hacer en un proyecto de esta magnitud es la elección de un escáner apropiado a la escala del proyecto. En el mercado existen una gran variedad de escáneres láser que permiten una amplia gama de escalas, desde los escáneres de tiempo de vuelo LIDAR aéreos $(20 \mathrm{~km}-50 \mathrm{~m})$ y terrestres $(300 \mathrm{~m}-2 \mathrm{~m})$, hasta escáneres láser de fase, ideales para escalas pequeñas $(4 \mathrm{~m}-1 \mathrm{~cm})$. Estos instrumentos entregan los siguientes datos:

1. Posición y rotación del instrumento

2. Coordenadas espaciales: valor $X Y Z$

3. Intensidad: valor de reflectancia de los materiales

4. Color: valor RGB aquellos que incorporan cámaras digitales calibradas

Una vez elegido el escáner láser se puede planificar su posición de acuerdo a su alcance, el orden en que se tienen que realizar el levantamiento y el tiempo que se toma en realizar cada barrido. Con la finalidad de evitar retrasos en la toma de datos se deben de tomar en cuenta las siguientes consideraciones:

Problemas administrativos y de gestión: son varios lo casos donde no es posible realizar el levantamiento en los horarios que más conviene, así como de las mejores posiciones por problemas con vecinos, tráfico, etc.

Condiciones climáticas: frío o calor extremo, lluvia, etc. hacen que las jornadas sean imposibles de cumplir.

Suministro de energía: todo necesita de baterías por lo que se tiene que estar preparado.

\section{Post proceso}

En esta etapa la información recogida en campo pasa una serie de procesos para filtrar y unir la información en un único modelo:

1. Limpieza: eliminar toda aquella información que no se desea, ya sea de forma manual o de forma automática. En ambos casos se requiere de personal capacitado que reconozca y valore la información que no pertenece al objeto de estudio.

2. Registro: encontrar la posición y rotación del instrumento para cada barrido en un sistema de coordenadas específico. Esto se puede hacer a través de puntos de control o programas de ingeniería inversa.

3. Optimización del modelo: creación de un modelo homogéneo. El modelo se estructura y divide en partes para facilitar su manejo y comprensión.

\section{Explotación 2D y 3D del modelo de nube puntos}

Extraer información 2D y 3D del modelo de nube de puntos generado es un proceso indispensable. Al avanzar la tecnología es cada vez es más sencillo visualizar y gestionar un mayor número de puntos en tiempo real. Los visualizadores permiten explorar el modelo y generar las vistas necesarias para una mejor comprensión del objeto de estudio. ${ }^{3}$

\footnotetext{
${ }^{3}$ Bonora L., Colombo L., Marana B., 2005. Laser Technology for cross-section survey in ancient buildings: a study for S.M. Maggiore in Bergamo. CIPA 2005 XX International Symposium. Torino, ITALY
} 
Las principales ventajas de utilizar esta metodología en la creación de un modelo de nube de puntos son:

El levantamiento no se limita el uso de un solo instrumento gracias a la incorporación en el registro de programas de ingeniería inversa.

Se reduce tiempo en campo de manera significativa gracias a la reducción en el uso de puntos de control. Por una parte no es necesario montar y desmontar las dianas y el tiempo de barrido se reduce hasta en una tercera parte.

Se consiguen resultados válidos alternativos si se aprovecha la gran densidad de puntos que generan los escáneres láser y evita el complejo proceso de triangulación de la nube de puntos.

La eficiencia de los escáneres láser en la captura de información 3D en poco tiempo y un post proceso continuo, plantean nuevas formas de documentar el Patrimonio Arquitectónico.

\section{Captura de datos}

Se utilizó un escáner láser RIEGL Z420i combinado con una cámara reflex digital calibrada Nikon D100 para el levantamiento de la Iglesia de Santa María del Mar. Este escáner láser tiene una precisión de $4 \mathrm{~mm}$ promedio @ $50 \mathrm{~m}^{4}$ y su rango de acción es de $2 \mathrm{~m}$ a $250 \mathrm{~m}$. Su campo visual de $80^{\circ} \times 360^{\circ}$ lo hace un equipo ideal para la escala de este edificio.

Debido a que Patrimonio Arquitectónico establece la escala 1:100 y 1:50 para plantas, secciones y alzados, y escala 1:25 para detalles significativos, la resolución del modelo de nube de puntos quedó en $5 \mathrm{~cm}$ para el modelo general y $3 \mathrm{~cm}$ para las áreas que exigían mayor detalle. Esta resolución se estableció considerando los siguientes puntos con el fin de asegurar una toma de datos apropiada y de alta calidad:

\section{Densidad de puntos y Oclusiones}

La adquisición de una alta densidad de puntos aleatoria puede describir de manera correcta un elemento arquitectónico. Aunque es debatible los rangos que diferencian la escala urbana, la arquitectónica y la escultórica, este proyecto considera que la escala arquitectónica ocupa el rango de $15 \mathrm{~cm}$ a $100 \mathrm{~m}$. Por esta razón el modelo general presenta una resolución de $5 \times 5 \mathrm{~cm}$, resolución mínima para detectar un detalle de $15 \mathrm{~cm}$ con un $68 \%$ de fiabilidad según la fórmula $Q=1-(m / \lambda)^{5}$.

Las oclusiones se redujeron planificando previamente las posiciones del escáner láser. El proyecto se dividió en dos partes; una interior y otra exterior. Se comenzó por el levantamiento interior en el que se realizaron 16 posiciones generales y 22 de detalle correspondiente a cada capilla. El exterior se dividió en tres partes; el nivel de la calle, el primer nivel, y la cubierta, para un total de 64 posiciones generales. Los escáneres con mayor detalle se realizaron en los accesos al Templo y en el Rosetón.

\footnotetext{
${ }^{4}$ Technical Data for LMS-Z420i. www.riegl.com

${ }^{5}$ Mills J., Barber D., 2003. An Addendum to the Metric Survey Specifications for English Heritage -The Collection and Archiving of Point Cloud Data obtained by Terrestrial Laser Scanning or other methods. Newcastle, U.K.
} 


\section{Sistema de coordenadas}

Se establecieron dos sistemas de coordenadas; el que utiliza el Instituto Cartográfico de Cataluña para el área metropolitana de Barcelona; European Datum 51 zona $31 \mathrm{~N}$, y uno propio en el eje del acceso principal para facilitar la lectura y generación de planos en CAD.

\section{Sistema para el Registro}

Conocer la forma de registro en la etapa del post proceso para los barridos planificados disminuye de forma significativa el tiempo de captura en campo. Contar con el registro a través de programas de ingeniería inversa reduce la colocación de puntos de control; esto reduce el tiempo que se utiliza en colocarlos y recuperarlos, y el tiempo de barrido por cada posición. Solo se colocaron puntos de control en los barridos generales para georeferenciar el proyecto y controlar su precisión general.

La captura de datos se realizó en 8 días hábiles; tres días para la nave central y el ábside, un día para la cripta, un día para la capilla del Santísimo, un día para el exterior nivel +1.50 , un día para el primer nivel y un día para la cubierta. Se realizaron 132 posiciones. En el caso de no tener que realizar el barrido de los puntos de control es posible llegar a realizar hasta 30 posiciones en una sola jornada, lo que significa tomando $2.5 \mathrm{M}$ de puntos promedio/barrido hasta $75 \mathrm{M}$ de medidas en un solo día. Esta enorme cantidad de datos en tan poco tiempo es la mayor ventaja que ofrece este tipo tecnología.

\section{Post proceso}

El post proceso fue realizado por dos personas en un periodo de un mes, esto representa una gran eficiencia en el proceso de gestión de los datos y una de la mayores ventajas cuando se compara contra cualquier sistema de topografía tradicional.

\section{Limpieza}

Manual: al tener la información en 3D es relativamente sencillo eliminar aquellos objetos no deseados en el modelo. Los programas de los escáneres de tiempo de vuelo han mejorado de forma considerable este proceso. La manera de seleccionar o deseleccionar puntos de la nube de puntos es bastante amigable. Personas, andamios, automóviles... la lista de objetos a eliminar de cada escena puede variar de un proyecto a otro y sería absurdo esperar a que esto se transforme en un proceso enteramente automático en algún futuro cercano. Siempre se necesitará de un técnico especialista que finalmente valore la información que no se tiene que eliminar.

Automática: La eliminación de ruido del escáner se logra mediante el algoritmo que permite eliminar aquellos puntos según una distancia mínima y determinado número de puntos. Este proceso automático es bastante útil para minimizar el número de puntos válido por barrido. 
Fig. 2: Datos no deseados seleccionados de forma manual para su eliminación en un barrido con RiscanPro.

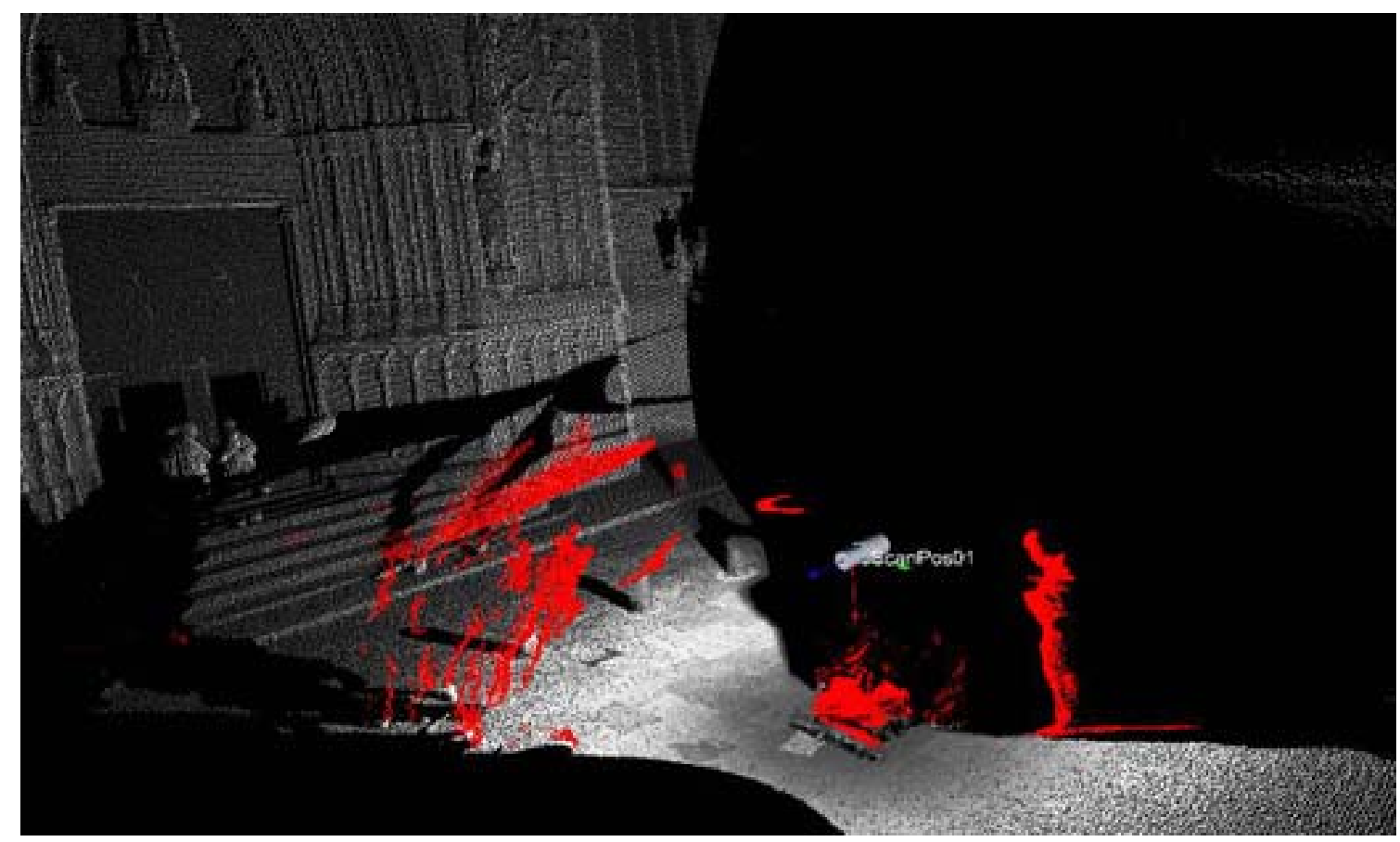

\section{Registro}

Se utilizaron dos sistemas para el registro de los datos capturados:

Barridos generales se registraron a través de puntos de control con topografía tradicional utilizando el sistema desarrollado por RIEGL a través de su programa RiscanPro ${ }^{6}$. El sistema reconoce cilindros o puntos planos de $5 \mathrm{~cm}$ de forma automática en cada barrido y lo registra, siempre y cuando exista un mínimo de tres puntos de control comunes entre los barridos. El sistema permite incorporar los valores de una estación total para georeferenciar el modelo. Tener puntos de control para todas las posiciones es excesivo y hace que la toma de datos sea ineficiente e imprecisa, varios casos se nos han presentado en proyectos anteriores donde personas y animales mueven los puntos de control y se tiene que repetir la captura de datos.

Los barridos de detalle se registraron a través de distintos programas comerciales de ingeniera inversa: Rapiform (Inus Technology), Geomagic Studio y Polyworks (Innovmetric). Estos programas permiten la obtención de los valores de rotación y traslación del escáner de una manera eficiente y de manera precisa. Este registro no requiere de puntos de control, y utiliza

\footnotetext{
${ }^{6}$ Neubauer W., Doneus M,, Studnicka N., Riegl J., 2005. Combined High Resolution Laser Scanning and Photogrammetrical Documentation of the Pyramds art Giza. CIPA 2005 XX International Symposium. Torino, ITALY.
} 
las diferencias en la geometría del barrido para el registro. Este registro permite reducir de manera significativa los tiempos de captura de datos en campo.

Por lo general todos los escáneres que utilizan puntos de control requieren de tres barridos por posición; uno general que se utiliza para reconocer los puntos de control, un barrido a máxima resolución de cada punto de control, y el barrido de la resolución elegida para capturar los detalles. Al eliminar los puntos de control es posible eliminar los primeros dos barridos y maximizar el tiempo para la toma de datos. Este sistema permite integrar barridos de otros escáneres láser a un mismo proyecto. Por otra parte realizar todos el registro con este método dificulta el control de la precisión del proyecto global, cuando se unen más de 60 barridos en un solo modelo de puntos no se tiene forma de comprobar los errores de registro a menos que se utilice topografía tradicional.

Fig. 3: Registro de barridos de detalle de la nave central a través de Polyworks (Innovmetric).

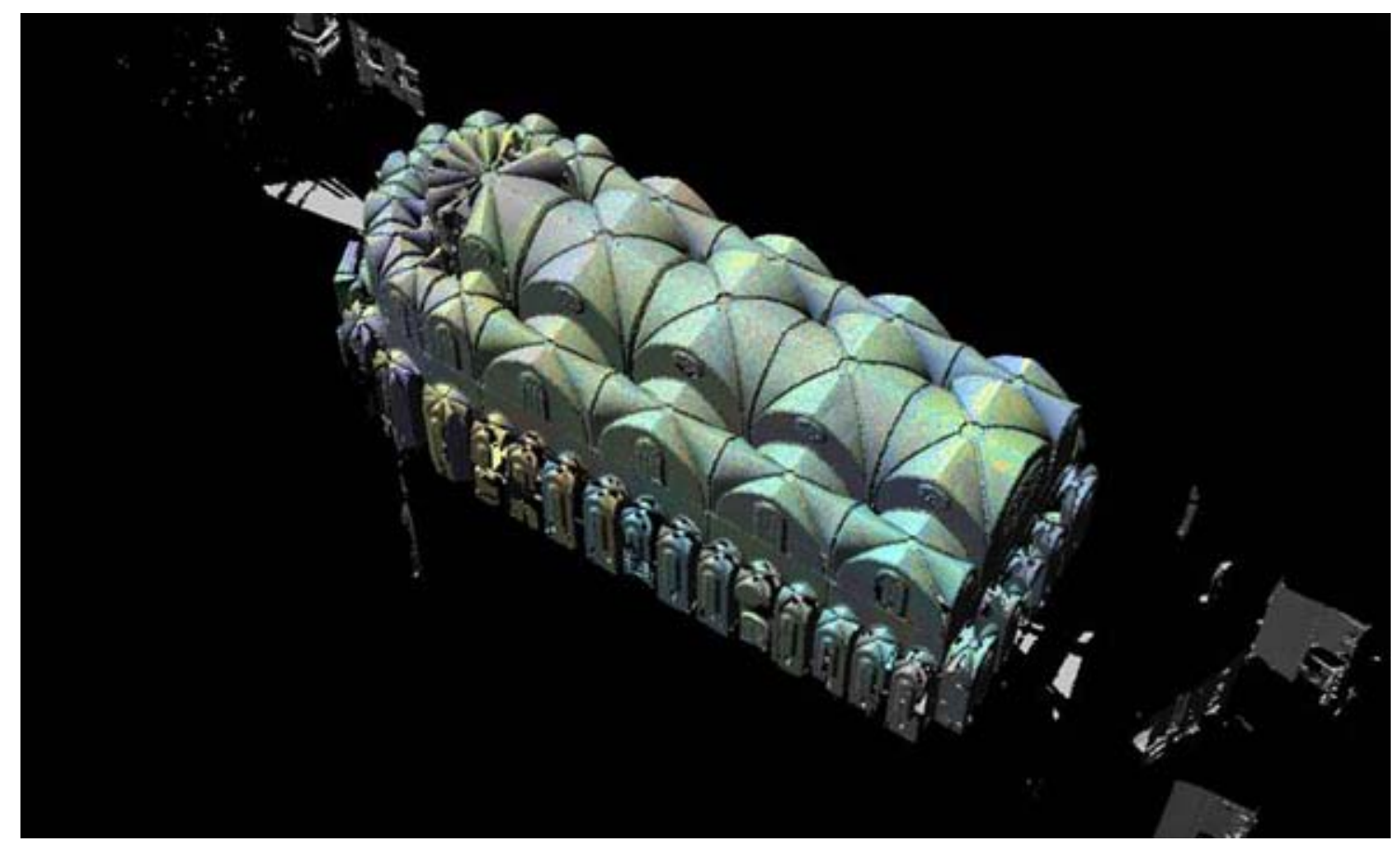

\section{Optimización}

Una vez se tienen todos los barridos en un mismo sistema de coordenadas, se procede a la unión de los barridos. Es en este paso donde se aplica la resolución del modelo elegido, en este caso $5 \mathrm{~cm}$ para el modelo general y $3 \mathrm{~cm}$ para las áreas que requerían mayor detalle. $\mathrm{El}$ algoritmo basado en octree permite determinar la distancia mínima entre los puntos de la nube de puntos y eliminar las duplicidades de puntos a causa de las distintas posiciones del escáner láser. 
Para manipular y visualizar de forma correcta el modelo se Santa Maria del Mar se dividió en las siguientes partes:

Resolución / M puntos / \# barridos / Gbytes

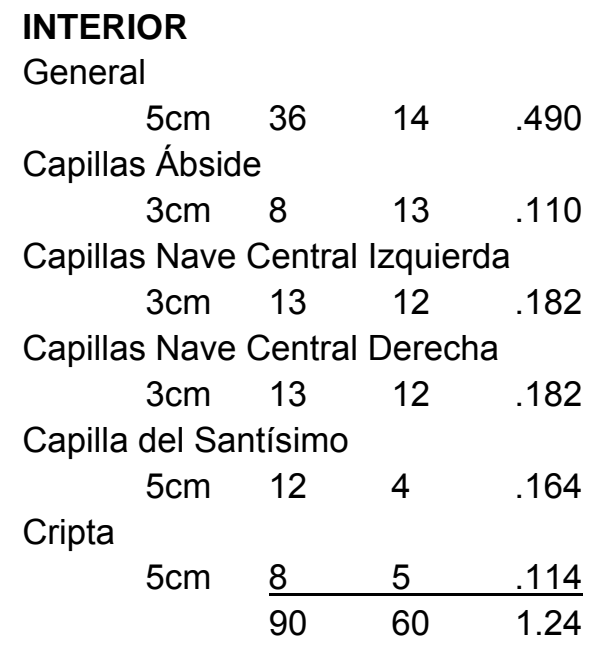

\section{EXTERIOR}

Contexto

Nivel Calle

$10 \mathrm{~cm} \quad 12 \quad \mathrm{~s} / \mathrm{n} \quad .095$

$5 \mathrm{~cm} \quad 50 \quad 21 \quad .705$

Primer Nivel

$5 \mathrm{~cm} \quad 14 \quad 34 \quad .195$

Nivel Cubierta

$5 \mathrm{~cm} \quad$\begin{tabular}{lll}
14 & 17 & .195 \\
\hline 90 & 72 & 1.19
\end{tabular}

$\begin{array}{llll}\text { TOTAL } & 180 & 132 & 2.43\end{array}$

La estructura de la información mantuvo la estructura de la toma de datos, el interior se dividió en seis partes; una general de toda la nave, y cinco de detalle (una de las capillas correspondientes al atrio, otra para las capillas laterales izquierda y derecha, la capilla del Santísimo y la cripta). Mientras que la exterior se mantuvo en cuatro partes; una general de contexto, y tres correspondiente a los principales niveles.

\section{Modelo de nube de puntos}

El resultado final del levantamiento con láser escáner es un modelo de 180M de puntos (XYZ, i, RGB) georeferenciado. Sin embargo una de las mayores deficiencias ha sido una extracción rápida y ágil de información $2 \mathrm{D}$ y $3 \mathrm{D}$ del modelo. La mayoría de los visualizadores de nubes de puntos son versiones acotadas de programas propios de los escáneres láser (RiscanPro, 
Cyclone, Rapidform, etc). Se necesita de usuarios experimentados para extraer esta información. Existen otros visualizadores que se ejecutan dentro de programas CAD (Pointcloud, Cloudworx) pero requieren ordenadores potentes para mover de una manera eficiente una gran cantidad de puntos.

Fig. 4: Visualización del interior del modelo de nube de puntos. (Imagen estereoscópica)

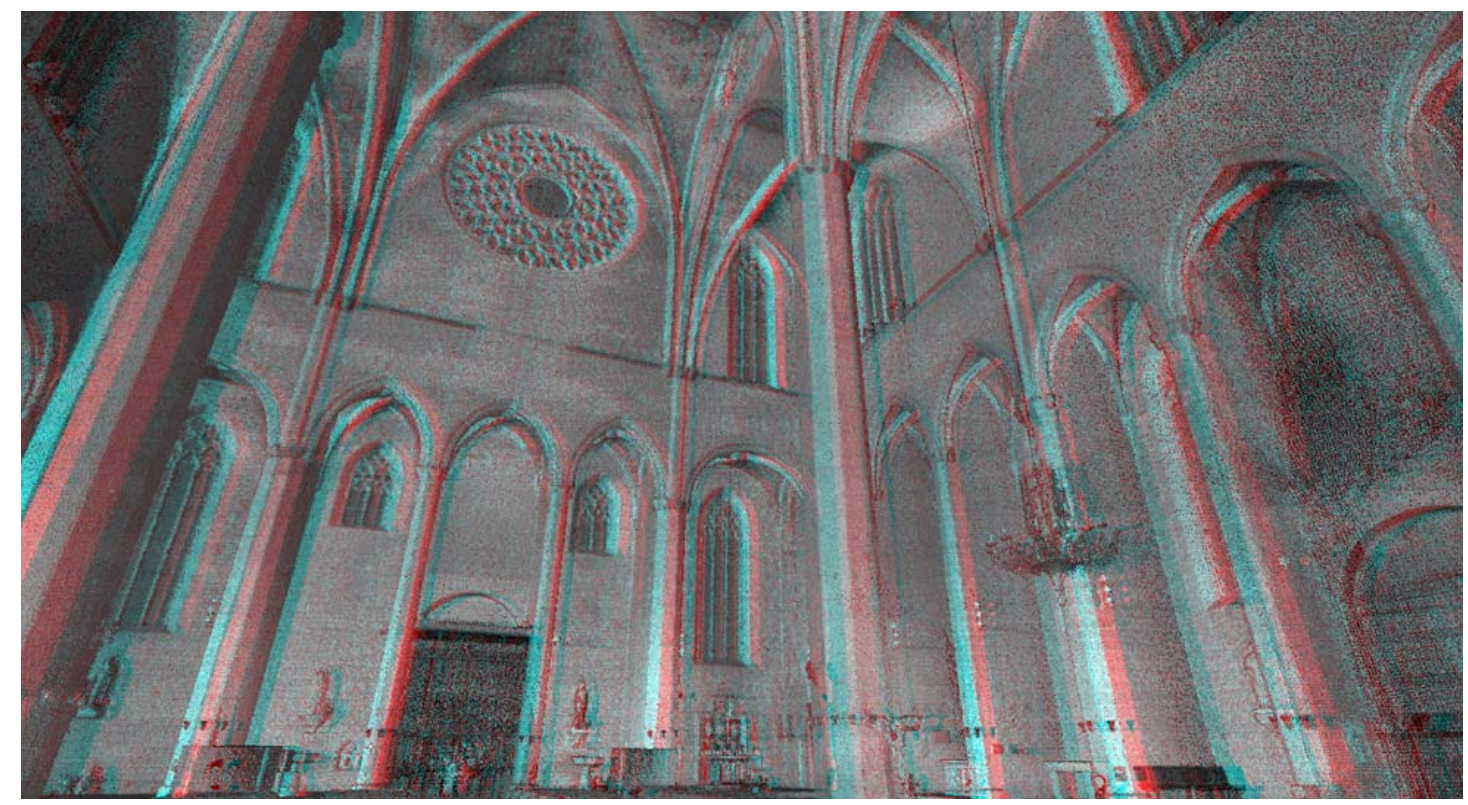

La extracción de información $2 \mathrm{~d}$ y $3 \mathrm{~d}$ de este modelo se realizó con un pequeño visualizador llamado Pointools ${ }^{7}$. Este programa puede manipular de forma eficiente modelos 3D de hasta $120 \mathrm{M}$ de puntos en tiempo real. Una de sus principales ventajas es la fácil extracción de imágenes con una resolución determinada del modelo 3D. Es posible realizar cualquier vista o sección que se necesite y generar un archivo de imagen.

Uno de los problemas a solucionar fue la generación de una imagen que sirviera como plano arquitectónico para su incorporación en un programa de CAD. Por esa razón cada plano se formó uniendo tres imágenes: una sección de $3 \mathrm{~cm}$ de espesor de la nube de puntos (color rojo), una del fondo, y otra del fondo con sombras. Finalmente se adopto para el tamaño de la imagen formatos DIN A3 y DIN A2.

Para que la imagen presentara suficiente calidad para describir la morfología del edificio se utilizaron las siguientes resoluciones para cada escala:

Escala 1:200 a 50 pixel/cm, escala 1:100 a100 pixel/cm, escala $1: 50$ a 200 pixel/cm y escala $1: 25 \mathrm{a} 400 \mathrm{pixel} / \mathrm{cm}$.

El segundo resultado fue la generación de: 8 plantas, 22 secciones, 6 alzados, y 6 detalles. Estas imágenes incorporadas en programas de CAD tradicional, se utilizaron para el diagnóstico de las deformaciones, el desplome de las estructuras, y toma de medidas en

\footnotetext{
${ }^{7}$ High Performance Point Cloud Software. www.pointools.com
} 
general. En algunos casos se utilizaron imágenes digitales de alta resolución unidas a las ortoimágenes de nubes de puntos para facilitar la interpretación en zonas puntuales.

\section{Fig. 5: Ejemplo de sección transversal hacia el Rosetón.}

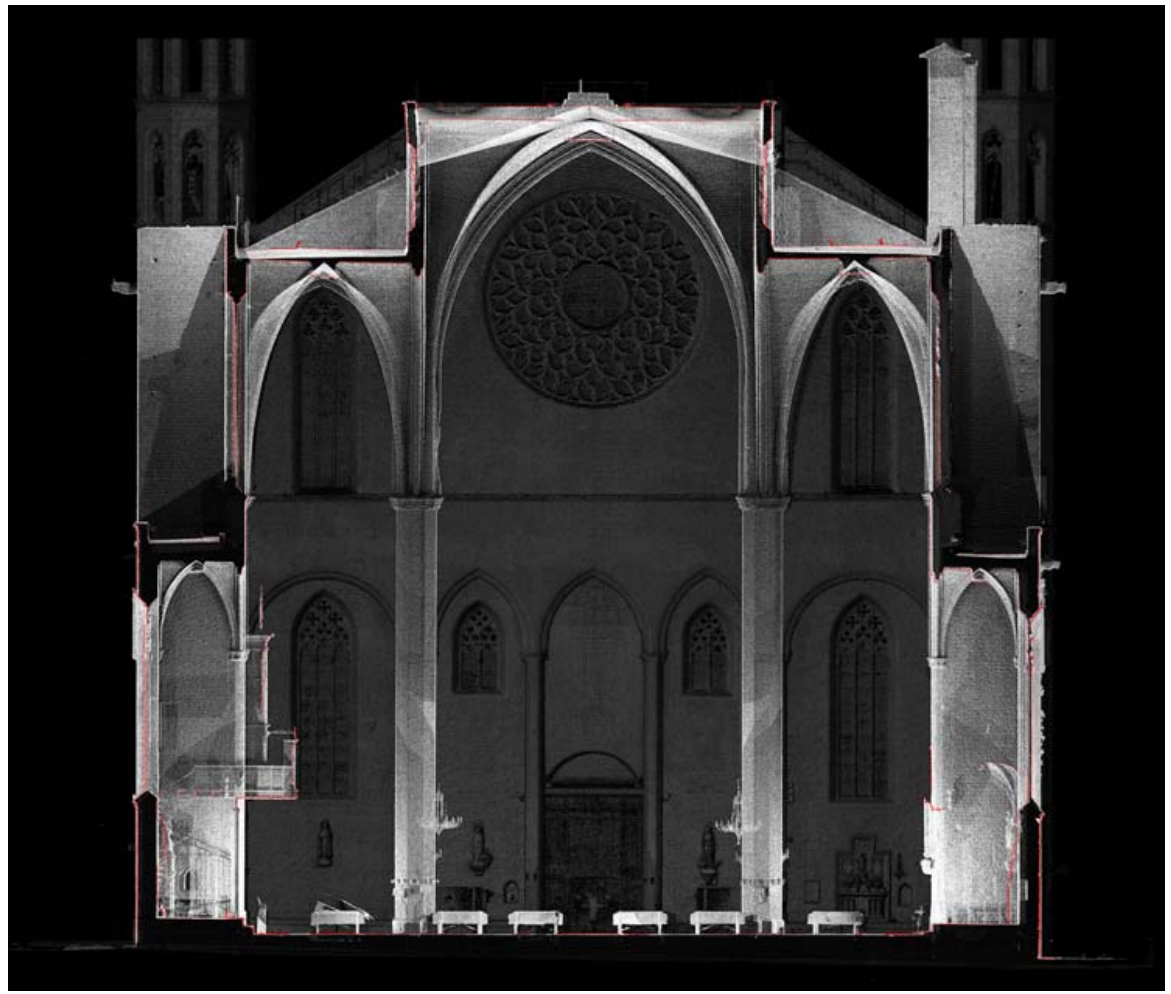

\section{Conclusiones}

El escáner láser permite realizar una gran adquisición de datos en un breve periodo de tiempo, la metodología adoptada aprovecha esta ventaja, y optimiza de manera significativa la toma de datos al evitar la colocación de un número significativo de puntos de control. El tiempo del registro en post proceso se optimiza realizando una parte a través de programas de ingeniería inversa y generando orto imágenes de nubes de puntos densas evitando el largo proceso de generación de polígonos.

La generación de orto imágenes (plantas, secciones, alzados) a partir de un solo modelo global de puntos evita los errores comúnmente generados por la topografía tradicional en la generación de planos CAD de inmuebles complejos. La aplicación de esta tecnología en el levantamiento de inmuebles arquitectónicos no substituye métodos ampliamente aceptados (ej. Fotogrametría) en el registro del Patrimonio Arquitectónico. Sin embargo la gran generación de información 3D sin necesidad de interpretación, procesada de forma correcta presenta nuevas maneras de "conocer" en un mundo digital la realidad arquitectónica. 